\title{
İnflamatuvar barsak hastalığı olan çocuk hastalarımızın değerlendirilmesi
}

\author{
Clinical evaluation of children with inflammatory bowel disease
}

\section{Eylem SEVINÇ}

Sağllk Bilimleri Universitesi Kayseri Eğitim ve Araştırma Hastanesi Çocuk Gastroenteroloji Kliniği, Kayseri

Giriş ve Amaç: Görülme sıklığı çocuklarda son yıllarda giderek artan inflamatuvar barsak hastalığı tanısı almış olgularımızın demografik, klinik ve laboratuar bulguları ve izlem sonuçlarının değerlendirilmesi amaçlanmıştır. Gereç ve Yöntem: Bu çalışmada Sağlık Bilimleri Üniversitesi Kayseri Eğitim ve Araştırma Hastanesi Çocuk Gastroenteroloji bölümünde, 2014 - 2017 yılları arasındaki süreçte izlenen yaşlan 4-18 yas arasında değișen, 16'sı erkek (\%50), 32 inflamatuvar barsak hastalığ olan olguların başvuru şikayetleri, fizik muayene bulguları, laboratuvar ve endoskopik verileri ve aldıkları tedavileri retrospektif olarak değerlendirildi. Bulgular: Çalışmaya alınan 32 olgunun yas ortalaması 15 yıl ve 16'sı (\%50) erkek idi. Olguların 22'sinde ülseratif kolit (\%68), 10'nunda Crohn hastalı̆g (\%32) saptandı. Ülseratif kolitli olgularımızın en sık başvuru șikayeti kanlı dışkılama (\%95), Crohn hastalıklı olgularımızn ise karın ağrısıydı (\%90). Olgularımızda batın hassasiyeti en sık görülen fizik muayene bulgusuydu. Inflamatuvar barsak hastalıklı olgularımızın kolonoskopik bakılarında, ülseratif kolitli olgularımızın 12'sinde (\%55) pankolit, Crohn hastalıklı olgularımızın 6'sinda (\%60) ileokolonik tutulum gözlendi. Inflamatuvar barsak hastalıklı olgularımızın izlem sırasında 30'unun (\%96) mesalazin, 24'ünün (\%77) steroid ve 23'ünün (\%72) azatiopurin aldığı saptanırken, diğer taraftan 6 (\%18) olgumuzun biyolojik ajan aldığı, 1 (\%3,1) olgunun da metotreksat aldığı, 3'üne (\%9.3) cerrahi girişim uygulandığı saptandı. Sonuç: Inflamatuvar barsak hastalıkları çocukluk çağının önemli kronik hastalıklarından biridir. Uzun dönemli takip gerektiren çocuk olgularda gerek hastalığa gerekse uygulanan tedavilere bağlı olarak gelişen komplikasyonların sıklı̆̆ı giderek artmaktadır.

Anahtar kelimeler: Ülseratif kolit, Crohn hastalığı, çocuk

\section{GİRISs}

Inflamatuvar barsak hastalıkları (IBH) barsak mikroflorasına karşı gelişen anormal immün yanıtın neden olduğu kronik, idiyopatik inflamasyonla karakterize olan bir hastalık grubudur. Kolona sınırlı tutulum gösteren ülseratif kolit (ÜK) ve gastrointestinal sistemin herhangi bir seğmentini tutan Crohn hastalığı $(\mathrm{CH})$ olmak üzere 2 majör klinik formdan oluşur. Diğer bir formu ise indetermine kolittir (1). Gerek ÜK gerekse $\mathrm{CH}$, geç adolesan ve genç erişkin dönemi hastalıkları olup yaşamın 2. dekatında artı̧ gösterir (2).

Ülkemizde çocuklarda IBH insidansı saptayan kapsamlı bir çalışma olmamasına rağmen bu hastalıkların çocuklarda görülme sıklığı son yıllarda giderek artmıştır (3). Batı ülkelerindeki çocuklarda $\mathrm{CH}$ insidansı 0.2-8.5/100.000 iken ÜK insidansı 0.5-4.3/100.000 olarak bildirilmiştir. Bu oranlar
Background and Aims: The aim of this study was to evaluate the demographics, clinical, laboratory findings, and results of follow-up of our cases with inflammatory bowel disease increasing incidence of in children. Materials and Methods: This study was carried out in the Department of Pediatric Gastroenterology of Kayseri Education and Research Hospital of Health Sciences University between the years 2014 and 2017 and included 32 cases of Inflammatory bowel disease, 16 cases (50\%) of men aged between 4 and 18 years. Physical examination findings, laboratory and endoscopic results as well as treatments of our cases, were evaluated retrospectively. Results: The mean age of the 32 cases enrolled in this study was 15 years, and 16 cases (50\%) were male. Ulcerative colitis was found in 22 cases (68\%), Crohn's disease was found in 10 cases (32\%). The most frequent complaints of our patients with ulcerative colitis were bloody stool (95\%), and patients with Crohn's disease were abdominal pain (90\%). In our cases, the most common physical examination finding was the abdominal tenderness. In our colonoscopic assessment, we detected pancolitis in 12 ulcerative colitis cases (55\%), and found ileocolonic involvement in 6 Crohn's disease cases (60\%). During the follow-up of our cases with inflammatory bowel disease, we identified $30(96 \%)$ cases received mesalazine, 24 (77\%) cases received steroids, and $23(72 \%)$ cases received azathioprine. In addition, we learned 6 (18\%) cases received biochemical agents, 1 (3.1\%) case received methotrexate, and 3 (9.3\%) cases had surgery. Conclusion: Inflammatory bowel disease is one of the most important chronic diseases of childhood. In children who require long-term follow-up, the frequency of complications due to illness or treatment is increasing.

Key words: Ulcerative colitis, Crohn's disease, child

kıyaslandığında çocuklarda CH'nın, ÜK'den daha fazla görüldügünü ortaya koymaktadır (4). IBH'nın belirtileri genellikle tutulan intestinal seğment alanına göre değişir. $\mathrm{CH}$ olan çocuklarda tekrarlayan karın ağrıları kilo kaybı ve ishal, ÜK olan çocuklarda kronik ishal ve hemotokezya ön plandaki bulgulardır. Üst ve alt endoskopik bakı ve histopatolojik değerlendirme tanıdaki en değerli yöntemdir. IBH olan çocukların tedavisinde en az yan etkiyle optimal yaşam şartlarını sürdürmek için farmakolojik, nütrisyonel ve cerrahi yaklaşımlar uygulanmaktadır $(5,6)$.

Bu çalışmada 2014-2017 yılları arasında Kayseri Eğitim ve Araştırma Hastanesinde IBH tanısı olan 32 çocuk hastanın demografik, klinik ve laboratuvar bulguları ve izlem sonuçlarının değerlendirilmesi yapıldı. 


\section{GEREÇ ve YÖNTEM}

Araştırmaya Sağlık Bilimleri Üniversitesi Kayseri Eğitim ve Araştırma Hastanesi Çocuk Gastroenteroloji Bölümü'nde, Aralık 2014 - Şubat 2017 tarihleri arasında retrospektif olarak iki yıllık süreçte izlenen yaşları 4-18 yaş arasında değişen 16'sı erkek (\%50) olan 32 IBH'lı çocuk dahil edildi. Çalışmaya dahil edilen hastalarda, yaş ve cinsiyet dağılımı, tanı alma yaşı, başvuru yakınmaları, fizik muayene bulguları, tam kan sayımı, sedimentasyon hızı, gayta incelemesi, biyokimyasal ve serolojik tetkikleri ile endoskopik ve histopatoloji sonuçları, aldıkları tedaviler açısından değerlendirildi.

İstatistiksel analizlerde sonuçlar, ortalamalar \pm SD veya medyan (aralık) olarak ifade edildi. Normalliği belirlemek için Shapiro Wilk testi uygulandı. Normal dağılıma uymayan verilerin karşılaştırılmasında Mann-Whitney U testi, normal dağılıma uyan verilen karşılaştırılmasında student t-testi ile analiz yapıldı (SPSS for Windows 21). Çalışma için etik kurul onayı 2017/52332816 sayı no ile Sağlı Bilimleri Üniversitesi Kayseri Eğitim ve Araştırma Hastanesi Eğitim Planlama Kurulu'ndan alındı.

\section{BULGULAR}

Araştırmaya alınan 32 IBH olgusunun 16'sı kız (\%50), 16’ı erkek (\%50) olup, yaşları 4-18 yıl arasında (ortanca 15 yıl) değişmekteydi (E/K=1). Hastaların 22'sinde ÜK (\%68), 10'nunda CH (\%32) saptandı. ÜK'li olgularımızın 12'si (\%60) erkek 10 tanesi (\%40) kız, yaşları 4-18 yıl arasında (ortanca 14 yıl) değişmekteydi. CH'li olgularımızın 4'ü erkek (\%40) 6'sı (\%60) kız, yaşları 6-18 yıl arasında (ortanca 17.5 yıl) değişmekteydi. 2 ÜK'li olgumuzda 1. dereceden yakın akrabalarında IBH hastalığı olduğu öğrenildi. İBH'lı olgularımızın ortalama tanı yaşı 10,28 \pm 3.11 yıl iken, ÜK'li olgularımızın ortalama tanı

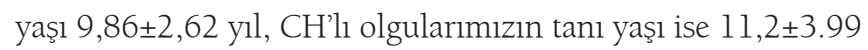
yıl olup demografik özelikler (Tablo 1)'de gösterildi.

\section{Tablo 1. Olguların demografik özelikleri}

$\begin{array}{lcc} & \text { Ülseratif Kolit (n=22) } & \text { Crohn Hastalı̆̆ }(\mathbf{n}=\mathbf{1 0}) \\ \text { Yaş (yıl) } & 14(4-18) & 17,5(6-18) \\ \text { Tanı alma yaşı (yıl) } & 9,86 \pm 2,62 & 11,2 \pm 3.99 \\ \text { Cinsiyet (E/K) } & 1.2 / 1 & 2 / 3 \\ \text { Boy (cm) } & 139,95 \pm 21,78 & 153,25 \pm 28,4 \\ & (112,5-161) & (125,2-172,33) \\ \text { Ağırlık (kg) } & 42,72 & 45,92 \\ \text { Aile öyküsü (n) } & (18,00-61,00) & (23,00-68,00)\end{array}$

Tablo 2. Olguların klinik ve laboratuvar özelikleri

\begin{tabular}{|c|c|c|}
\hline & Ülseratifi Kolit (n=22) & Crohn Hastalığı $(n=10)$ \\
\hline Kanlı dışkılama & $20(\% 95)$ & $6(\% 60)$ \\
\hline Karın ağrısı n (\%) & $11(\% 50)$ & $9(\% 90)$ \\
\hline Ateş n (\%) & $4(\% 22,7)$ & $8(\% 80)$ \\
\hline Tartı kaybı n (\%) & $5(\% 27)$ & $4(\% 40)$ \\
\hline Artrit n (\%) & $1(\% 4,5)$ & $2(\% 20)$ \\
\hline Eritema nodozum n (\%) & - & $1(\% 10)$ \\
\hline Lökosit (sayı/mm³) & $14.789 \pm 3.577$ & $20.400 \pm 5.415$ \\
\hline Hemoglobin (g/dl) & $11(7,5-12,4)$ & $9,5(7,5-10)$ \\
\hline Trombosit (sayı/mm³) & $454.430 \pm 96.200$ & $529.400 \pm 126.430$ \\
\hline Sedimantasyon hızı (mm/saat) & $40(12-110)$ & $66,5(22-118)$ \\
\hline FMF gen mutasyonu n (\%) & - & $3(\% 30)$ \\
\hline ILB12R defekti n (\%) & - & $1(\% 10)$ \\
\hline $\mathrm{p}-\mathrm{ANCA}(+) \mathrm{n}(\%)$ & $6(\% 27)$ & - \\
\hline $\operatorname{ASCA}(+) n(\%)$ & - & $2(\% 20)$ \\
\hline
\end{tabular}

FMF: Familial Mediterranean Fever (Ailevi Akdeniz Ateşi). p-ANCA: Peri-nükleer antistoplazmik antikor. ASCA: AntiSaccharomyces Cerevisiae antikoru 


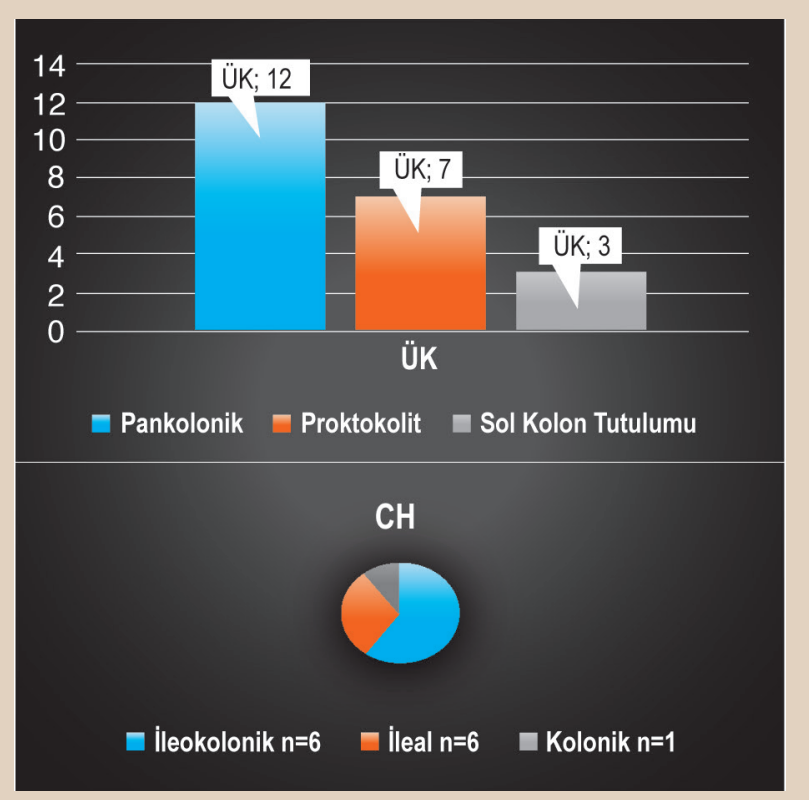

Şekil 1. Intestinal tutulum alanları.

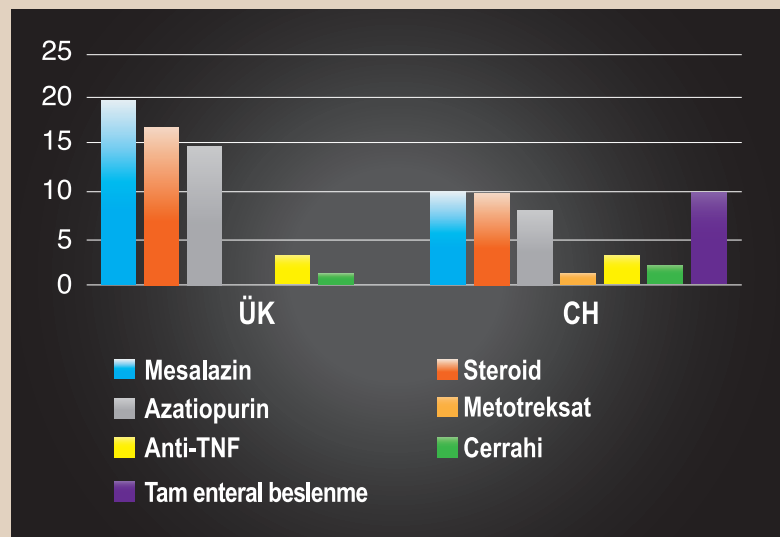

Şekil 2. Olguların aldıkları tedaviler. Anti-TNF: Anti tümör nekrozis faktör.

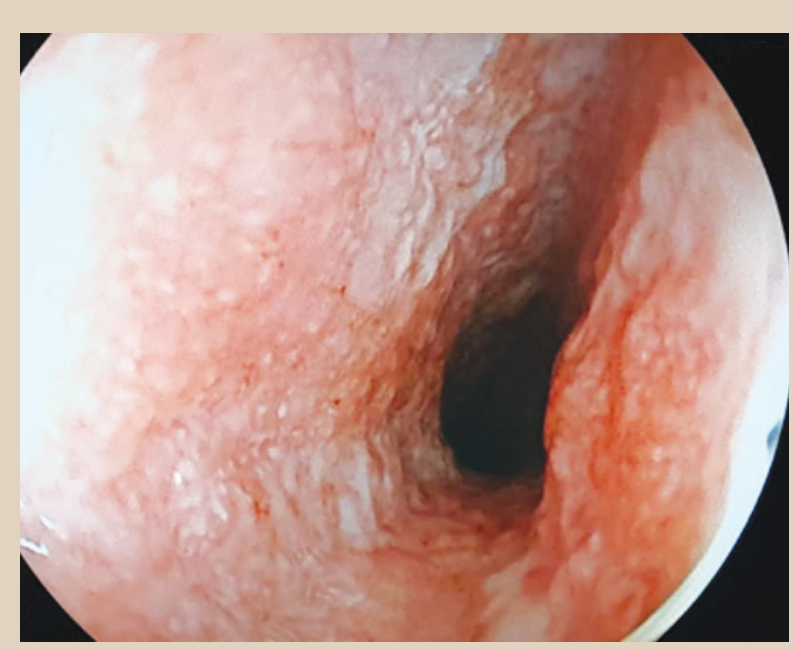

Resim 1. Ülsere eritemli kolon mukozası.
ÜK'li olgularımızın 20'sinde (\%95) kanlı dışkılama varken, 1 l'inde (\%50) karın ağrısı, 4'ünde (\%22,7) ateş, 5'inde (\%27) tartı kaybı mevcut iken CH'lı olgularımızın 9'unda (\%90) karın ağrısı, \%8'inde (\%80) ateş, 6’inda (\%60) kanlı dışkılama, 4'ünde (\%40) tartı kaybı saptandı. ÜK'li olgularımızın 1 tanesinde, CH'lı olgularımızın 3'ünde ekstraintestinal tutulum (eritema nodozum ve artrit) tespit edildi. CH'lı 1 olgumuzda Behçet hastalığı, 3 olguda da perianal fissür ve abse izlem sırasında gözlemlendi. IBH'lı olgularımızda tespit ettiğimiz muayene bulgularında batın hassasiyeti 21 (\%68), solukluk 18 (\%56) ve artrit 3 (\%6) olguda gözlemlendi.

Kemik mineral dansitometri (KMD) incelemesi yapabildiğimiz 32 olgumuzun 17'si $(\% 53,1)$ normal, 8'inde (\%25) osteopeni, 7'sinde $(\% 21,8)$ osteoporoz saptand. Kemik mineral yoğunluğunu gösteren yaşa göre $\mathrm{Z}$ skoru değerleri $\geq-2$ saptanan çocuklar "osteoporoz"; -1 ve -2 arasinda saptanan çocuklar "osteopeni” olarak tanımlandı. CH'lı olgularımızın 3'ünde (\%30) M694V Ailevi Akdeniz Ateşi (FMF) gen mutasyon saptanırken ÜK'li olgularımızın hiçbirinde FMF gen mutasyonu saptanmadı. IBH'lı olgularımızın serolojik tetkik sonuçlarına bakıldığında, ÜK'li hastalarımızın 6'sında (\%27) peri-nükleer antistoplazmik antikor (p-ANCA) pozitifliği varken, CH'lı olgularımızın 2'sinde (\%20) antisaccoromyces cerevia (ASCA) pozitifliği tespit edildi. CH'lı olgularımızdan 1 tanesinde ILB12R defekti tespit edilmiş olup olguların laboratuvar verileri (Tablo 2)'de gösterildi.

IBH'lı olgularımızın kolonoskopik bakılarında, ÜK'li olgularımızın 12'sinde (\%55) pankolit, 7'sinde (\%35) proktokolit, 3'ünde (\%10) sol kolon tutulumu gösteren kolit gözlenirken, CH'lı olgularımızın 6'sında (\%60) ileokolonik, 3'ünde (\%30) ileal, ILB12R defekti olan hastamızda kolonik tutulum gözlendi (Şekil 1). Kolonoskopi sırasında alınan biyopsi örneklerinde ÜK'li olgularımızın tamamında lamina propriada mononükleer hücrelerden zengin inflamatuvar hücre birikimi ve kriptlerde destrüksiyonu saptanırken, CH'lı olgularımızda sadece 2 olguda (\%20) granülom saptandı. Usst endoskopik bakı incelemelerinde ise sadece CH'll 2 olguda duodenumda multiple aftöz ülserler saptandı. Tanı sırasında ÜK'li hastalarımızın pediatrik ülseratif kolit aktivite indeks (PUCAI) skoruna göre 13'ünde (\%60) ağır şiddette (PUCAİ skor >65), 3'ünde (\%15) orta şiddete (PUCAI skor 35-64), 6'sinda (\%25) ise hafif şiddetli (PUCAİ skor <35) olduğu tespit edilirken, CH'lı olgularımızın Crohn hastalık aktivite indeksine (CHAi) göre 2'sinde (\%20) ciddi-fulminan hastalık (CHAi >40), 5'inde (\%50) orta şiddette hastalık (CHAi 30-37.5), 3'ünde (\%30) hafif şiddette hastalık (10-27.5) saptandı. MR-enterografi ile ince barsak incelemesi yapabildiğimiz CH'lığı olan olgularımızın 9'unda (\%90) ince barsak tutulumu gözlemlendi.

IBH'li olgularımızın izlem sırasında 30 (\%96) olgunun mesalazin, 24 (\%77)'ünün steroid ve 23'ünün (\%72) azatiopurin aldığı saptanırken, 6 (\%18) olgumuzun anti-tümör nekrozis 
(anti-TNF) ajan aldığı, 1 (\%3,1) olgunun da metotreksat aldığ saptandı. Tam enteral beslenme tanı esnasındaki tüm CH'ğ 1 olan olgulara başlanmasına rağmen sadece 2 olgu (\%20) bu beslenme tarzını tolere edebildi (Şekil 2).

ÜK'li olgularımızın remisyona girme süreleri $4.3 \pm 1.2$ hafta iken CH'lı olgularda bu süre daha uzun $(6.3 \pm 1.7$ hafta) olarak saptandı. Izlem sırasında 3 olguya (\%9) cerrahi müdahale yapildı (total kolektomi). Total kolektomi ve kolesistektomi yapılan ILB12R defekti olan kolonik tutulum gösteren CH'lı olgumuz izlem sirasında cerrahi komplikasyonlardan dolayı exitus oldu.

\section{TARTIŞMA}

Idiyopatik IBH, gastrointestinal kanalın kronik ya da tekrarlayan immün aktivasyon ve inflamasyonuyla karakterize olan hastalıklarıdır (Resim 1). Crohn hastalığı ve ülseratif kolit, idiyopatik IBH'nın 2 ana alt grubunu oluşturur (7).

Epidemiyolojik çalışmalar İBH'nın her yaşta görülebileceğini ortaya koymuştur. $\mathrm{CH}$ geç adolesan ve adult çağda, ÜK ise 10-18 yaş arasındaki çocuklarda pik yapmaktadır (8). Gerek ÜK'li gerekse CH'lı olgularımızın tanı yaşı 10 yıl civarındaydı. Çalışmamızda İBH'lı tüm olgularda E/K oranı 1 olarak saptandı. Bulduğumuz bu oran son yıllarda bildirilen diğer çalışma sonuçlarıla benzerdi. 2011 yılında Al-Qabandi ve arkadaşları Kuveytli IBH'lı çocuklarda yaptıkları çalışmada E/K oranını 1 olarak bildirmişlerdir. Diğer taraftan Kugathasan ve arkadaşları; Kuzey Amerika'da yaptıkları çalışmada hastalığın \%54-60 oranında erkek çocuklarda daha sık görüldüğünü saptamışlar (9,10). Dimakou ve arkadaşlarının 2015 yılında Yunanistan'da yaptıkları çalışmada; birinci dereceden akrabalarında IBH olanlarda IBH gelişme riskinin \%7 oranında arttığı tespit edilmiş (11). Çalışmamızda İBH'lı olgularımızın 2 tanesinde $(\% 6,2) 1$. dereceden yakın akraba pozitif aile öyküsü tespit etik. Bulduğumuz bu sonuç ülkemizinde içinde bulunduğu Akdeniz havzasında yapılan Dimakou ve arkadaşlarının yaptıkları çalışma sonuçlarıyla uyumluydu.

Çocukluk çağında IBH, inflamasyonun şiddetine ve intestinal sistemin tutulum yerine göre çok farklı bulgularla belirebilir. $\mathrm{CH}$ olanlarda karın ağrısı, ishal ve tartı kaybı ön plandayken ÜK'li olgularda kanlı ishal ön plandadır (12). Çalışmamızda ÜK'lı olgularımızda de en sık semptom kanlı dışkılamayken CH'lı olgularımızda ise karın ağrısıydı. Çocuk çağı IBH'lı olgularda artrit, anemi, eritema nodozum gibi ekstraintestinal sistem dışı tutulumların (EIST) CH'nda ÜK'e göre daha yaygın olduğu bildirilmiştir (13). Bizim çalışmamızda $3 \mathrm{CH}$ olan olguda ekstraintestinal sistem dışı tutulum varken, ÜK'li olguların hiçbirinde EIST olmadığı saptandı.

Anemi ve trombositoz IBH olan olgularda sıkça rastlanan bir laboratuvar bulgusudur (14). Olgularımızın başvuru anında anemi (\%56) ve trombositoz (\%64) olduğu saptandı. Remisyon sağladığımız tüm hastalarda anemi ve trombositozisin gerilediğini gözlemledik. Goodhand ve arkadaşları yaptıkları çalışmada çocukluk çağı IBH'de ilk tanı anında aneminin $\% 70$, ergenlerde ise \%42 oranında olduğunu tespit etmişler. Tedaviyle bunun çocuklarda \%15'a ergenlerde ise \%32'ye gerilediğini gözlemlemişlerdir. Çalışmamızda saptadığımız oranlar da bu çalışmayla uyumluydu. IBH Porto grubu 2016 yılında yaptıkları kesitsel çalışmada, İBH'lı çocuklarda \%20 -40 arasında değişen oranlarda \%16 p-ANCA ve ASCA pozitifliğinin olduğunu saptamışlar. Çalışmamızda p-ANCA ülseratif kolitli 6 (\%27) olgumuzda, ASCA ise CH'lı 2 (\%20) olguda müspet saptandı. Çalışmamızda CH'da ASCA, ÜK'de ise p-ANCA daha yüksek oranda saptandi.

IBD'li çocuklarda tedavideki temal amaç hastaları klinik remisyona sokmak ve remisyonu sürdürmektir. Genel olarak ÜK'li ve CH'lı olgularda bu amacı gerçekleştirebilmek için mesalazin, steroid ve immün modülatörler kullanılırken son zamanlarda transforming growth factor-beta (TGF-ß) içeren enteral beslenme ürünleri CH'lı olgularda kullanılmaya başlanmıştır $(17,18)$. Bizim çalışmamızda tam enteral beslenme ürünü kullandığımız CH'li hastalardan sadece 2'si (\%20) ürünü tolere edebilirken diğer hastalarımız tolere edemedi. IBH'lı olgularımızda remisyonun sürdürülmesi için mesalazin ve azatiopurin kullanıldı. ÜK'lı olgularımızdan 1 tanesinde pankreatit gelişmesi üzerine azatiopurin kesildi, diğer 1 CH'lı olgumuzda tiopurine yanıtsızlık nedeniyle ilaç kesilerek metotrexat başlandı. Son yıllarda gerek steroid bağımlı gerekse steroid dirençli olgularda, cerrahi girişim planlanan şiddetli seyir gösteren IBH'lı hastalarda anti-TNF ajanlar sıkça kullanılmaya başlanmıştır (19). Çalışmamızda 6 IBH’lı (\%18) hastamıza anti-TNF ajan olarak infliksimab başlandı, 1 olguda alerjik reaksiyon gelişmesi üzerine adalimumaba geçildi.

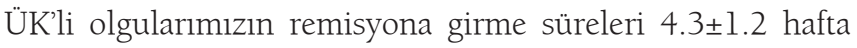
iken CH'lı olgularda bu süre daha uzun, 6.3 \pm 1.7 hafta, olarak saptandl.

Toksik megakolon, perforasyon ile komplike olmuş ve tıbbi tedaviye yanıtsız ÜK'lı olgular ile fibrostenotik hastalığı olan CH'lı olgulara cerrahi tedavi önerilmektedir. Yapılan çalışmalarda IBH'lı çocuk hastaların \%10'nunda cerrahi tedavi uygulandığı bildirilmiştir $(11,20)$. Bizim çalışmamızda ise 3 $(\% 9,3)$ olguya cerrahi uygulanmış olup, 2 ÜK'li olguya kolektomi, kolonik tutulum gösteren ILB12R defekti olan CH'lı 1 olgumuza tekrarlayan Salmonella septisemileri olması nedeniyle kolektomiyle birlikte kolesistektomi yapıldı.

Sonuç olarak IBH olan olgularımızı geriye dönük olarak değerlendirdiğimiz bu çalışmamızda; kronik inflamasyon ile seyreden diğer hastalıklar gibi IBH'nın çocuklarda sıklığının, morbiditesin ve komplikasyonlarının arttığını saptadık. 


\section{KAYNAKLAR}

1. Satsangi J, Silverberg MS, Vermeire S, et al The Montreal classification of inflammatory bowel disease: controversies, consensus, and implications. Gut 2006;55:749-53

2. Ye Y, Pang Z, Chen W et al. The epidemiology and risk factors of inflammatory bowel disease. Int J Clin Exp Med 2015;8:22529-42.

3. Beşer ÖF, Kutlu T, Çokuğraş FÇ, ve ark. Inflamatuvar barsak hastalığ tanılı çocukların uzun süreli izlemi: 53 olgunun değerlendirilmesi. Güncel Pediyatri Dergisi 2015;13:81-8.

4. MKoma AE. Inflammatory bowel disease: an expanding global health problem. Clin Med Insights Gastroenterol 2013;6:33-47.

5. Agrawal D, Rukkannagari S, Kethu S. Pathogenesis and clinical approach to extraintestinal manifestations of inflammatory bowel disease. Minerva Gastroenterol Dietol 2007;53:233-48.

6. Hyams JS. Treating inflammatory bowel disease in children and adolescents. Gastroenterol Hepatol 2014;10:444-6.

7. Reid G, Carey AF. Pathology of idiopathic inflammatory bowel disease. Surgery 2011;29:362-5.

8. Auvin S, Molinie F, Gower-Rousseau C, et al. Incidence, clinical presentation and location at diagnosis of pediatric inflammatory bowel disease: a prospective population-based study in northern France (1988-1999) J Pediatr Gastroenterol Nutr 2005;41:49-55.

9. Al-Qabandi WA, Buhamrah EK, Hamadi KA, et al. Inflammatory bowel disease in children, an evolving problem in Kuwait. Saudi J Gastroenterol 2011;17:323-7.

10. Kugathasan S, Judd RH, Hoffman RG, et al. Epidemiologic and clinical characteristics of children with newly diagnosed inflammatory bowel disease in Wisconsin: A statewide population-based study. J Pediatr 2003;143:525-31.
11. Dimakou K, Pachoula I, Panayotou I, et al. Pediatric inflammatory bowel disease in Greece: 30-years experience of a single center. Ann Gastroenterol 2015;28:81-6.

12. Griffiths AM. Specificities of inflammatory bowel disease in childhood. Best Pract Res Clin Gastroenterol 2004;18:509-23.

13. Bernstein $\mathrm{CN}$, Blanchard JF, Rawsthorne $\mathrm{P}$, et al. The prevalence of extraintestinal diseases in inflammatory bowel disease: a population-based study. Am J Gastroenterol 2001;96:1116-22.

14. Kulnigg-Dabsch S, Schmid W, Howaldt S, et al. Iron deficiency generates secondary thrombocytosis and platelet activation in IBD: the randomized, controlled thromboVIT trial. Inflamm Bowel Dis 2013;19:160916.

15. Goodhand JR, Kamperidis N, Rao A, et al. Prevalence and management of anemia in children, adolescents, and adults with inflammatory bowel disease. Inflamm Bowel Dis 2012;18:513-9.

16. Birimberg-Schwartz L, Wilson DC, Kolho KL, et al. pANCA and ASCA in children with IBD-unclassified, Crohn's colitis, and ulcerative colitis-a longitudinal report from the IBD Porto Group of ESPGHAN. Inflamm Bowel Dis 2016;22:1908-14.

17. Ruemmele FM, Veres G, Kolho KL, et al. Consensus guidelines of ECCO/ ESPGHAN on the medical management of pediatric Crohn's disease. J Crohns Colitis 2014;8:1179-207.

18. Turner D, Levine A, Escher JC, et al. Management of pediatric ulcerative colitis: joint ECCO and ESPGHAN evidence-based consensus guidelines. J Pediatr Gastroenterol Nutr 2012;55:340-61.

19. Ben-Horin S, Kopylov U, Chowers Y. Optimizing anti-TNF treatments in inflammatory bowel disease. Autoimmun Rev 2014;13:24-30.

20. Baillie CT, Smith JA. Surgical strategies in paediatric inflammatory bowel disease. World J Gastroenterol 2015;21:6101-16. 